\title{
One health behavior or many health-related behaviors?
}

\section{Jana Marie Havigerová Jaroslava Dosedlová Iva Burešová}

Institute of Psychology, Faculty of Arts, Masaryk Univeristy, 60300 Brno, Czech Republic
Correspondence: Jana Marie Havigerová Institute of Psychology, Faculty of Arts, Masaryk Univeristy, Arne Nováka I, 603 00 Brno, Czech Republic Email jamary@mail.muni.cz
This article was published in the following Dove Press journal: Psychology Research and Behavior Management

Objective: Of the many existing health models, models of health behavior are considered optimal for research and application as they focus on concrete forms of behavior that support, maintain, or undermine one's health, and they accentuate the individual as the initiator of this behavior. Research in this area follows a broad range of concrete partial manifestations of health behavior. Is it necessary to differentiate between various types of health behavior or could these partial manifestations be combined under one common scale?

Methods: Data acquisition tool: Health-Related Behavior Scale (HRBS, 42 items). Data processing methods: principal component analysis (the internal structure of HRBS), confirmatory factor analysis (the latent factor structure of four tested models). Sample: N=1,664 adult respondents. Results: The HRBS described ten areas of health-related behavior (ten extracted factors). All tested models of latent structure showed almost identical mathematical and statistical values of the model.

Conclusion: Health-related behavior includes a set of partial behaviors (behavior related to nutrition, addictive substances, movement, and physical exercises). An unambiguous latent factor structure has not been revealed. An open question remains whether there is one latent factor behind all health-related behaviors or whether there are multiple latent factors. The use of one or the other model should be deduced from the underlying theory and research objectives. To find a reliable model of health behavior, it is necessary to include moderators and mediators such as personality, attitude, or economic status.

Keywords: health-related behavior, model, latent variable analysis

\section{Introduction}

Currently, there are many different models of health existing parallel (such as the pathogenetic model, biomedical model, environmental-social model, and holistic model) that provide a theoretical basis for studying health and its context on various levels (intrapersonal, interpersonal, organizational, community, civic, environmental, societal, geopolitical, etc). ${ }^{1}$ In our studies, we work from the model of health behavior, which accentuates the individual as the initiator of behavior related to health. The production or inhibition of individual behavior is observed and analyzed under each behavioral model, and the consequences of this behavior on the individual's health are examined. ${ }^{2}$

Research on health behavior follows a broad range of concrete partial manifestations of health-related behavior. Most authors tend to differentiate at least two types of health-related behavior: health-supporting behavior and health-impairing behavior. Health-supporting behavior usually includes activities leading to good health and 
physical and psychological well-being such as adequate exercise, optimal nutrition, calorie-balanced diet, regular care for mental health, appropriate sleep regime, and prevention of risks. These are the components of health-supporting behavior with an influence repeatedly confirmed as protective in research studies..$^{2-4}$ Health impairing/damaging behavior includes activities that do not contribute to good health or mental and physical well-being, including drug abuse, inappropriate eating habits, insufficient sleep, bad hygiene, and various risky behaviors such as sexual behavior. ${ }^{5}$ The present research ${ }^{6,7}$ also uses the term health-directed behaviors $(H D B s)$, which are performed by an individual primarily to prevent disease, whereas health-related behaviors are those for which health is a byproduct. ${ }^{8}$

Experts, especially those focusing on the issue of changes in health behavior, ${ }^{9-11}$ must face the question of how many latent factors influence these partial manifestations of behavior. $^{12}$

\section{Unifactorial or multifactorial health behavior?}

Is health behavior represented by one factor or by many different factors? It is practically impossible to find an answer to this basic question in published research because 1) explicit statements by experts regarding this question are too varied and 2) most authors do not deal with this question explicitly but implicitly presume the existence of one or more latent factors. Several examples follow.

Some authors do consider various forms of health behavior but consider them as different demonstrations of one common factor. For instance, Donovan et $\mathrm{al}^{13}$ studied adolescents ( $N=1,280$ high school students and 2,219 university students) and worked with an extended list of six manifestations of health-related behavior (use of seatbelts, adequate hours of sleep, attention paid to healthy eating, adequate exercise, elimination of sedentary lifestyle, and regular tooth brushing). They worked with the scale in a unidimensional way; the degree of healthy behavior was determined by a sum of scores. Analogically, Goldenson et $\mathrm{al}^{14}$ used their self-report Pleasure and Health Behavior Inventory, which measured various forms of addictive, health-impairing behaviors. They confirmed the factor structure and strong internal validity of their scale, referring to a unifactorial structure. These researchers understand health-related behavior as a continuous bipolar scale with health-supporting behavior on one end and health-impairing behavior on the other end.

Other studies presume (or derive from data) various groupings of health-related behavior manifestations. A methodology based on grouping of behavior manifestations presumes a multifactorial model of health behavior. ${ }^{15}$ For instance, Skalamera and Hummer ${ }^{16}$ assessed individual forms of behavior dichotomously, either as health promoting or as health impairing. Individuals were assigned to one of three groups based on whether they produced health-promoting, health-impairing, or mixed behavior. Another example is the Mo-Mo study of Spengler et al, ${ }^{17}$ which used a cluster approach to behavior in three dimensions (physical activity, use of media, and eating). Four clusters of respondents were then identified (physically active, healthy eating, media, and low-scoring in all three observed dimensions).

The opinion presented by Strecher et $\mathrm{al}^{18}$ could be considered extreme - the author derives his approach to health-related behavior analysis from Bandur's model of selfefficacy. This model is based on the following sequence: person, expected efficacy, behavior, expected results, and results. The study by Strecher et al emphasized that self-efficacy refers to confidence in performing specific types of behavior in certain situations and not a personal trait that would work independently of contextual factors. Every particular behavioral manifestation needs to be assessed separately, as it is based on different levels of latent factors (eg, awareness of one's efficacy related to smoking, situational context, etc).

\section{Methods}

\section{The aim of the study}

The aim of this study is to examine whether different healthsupporting, health-impairing, or HDBs represent specific forms of health-related behavior or whether they are just different manifestations of the same basic health behavior phenomenon. The aim of the study is to find out whether there is only one common latent factor behind different manifestations of the health behaviors (unifactorial model) or whether there are many different latent factors (multifactorial model) in the background of different manifestations of health behavior (HB). It is not the subject of this study to reveal the identity of the latent factors that are behind the various manifestations of health-related behavior. This process was divided into two phases.

The aim of the first stage was to detect the internal factorial health behavioral structure for the of Health-Related Behavior Scale (HRBS). ${ }^{19,33}$ We assumed that the individual factors found represented specific types of health-related behavior.

The aim of the second stage was to find out whether there was one common latent factor or multiple latent factors behind different types of health behavior. Individual factors were grouped into different tested models according to the 
type of health-related behavior they represented: healthenhanced behavior (HEB), ${ }^{13,19,33}$ health-impaired behavior (HIB), ${ }^{5,19,33}$ and HDB. ${ }^{6,7,19,33}$ We operationalized these goals into the following research questions:

Question 1: How many specific types of health-related behavior can be distinguished on the basis of data obtained by the HRBS range? ${ }^{19}$ Each individual factor of the HRBS is considered to be a specific type of health-related behavior.

Question 2: How do different values show models of health-related behavior based on the assumption of a single vs several different operating latent factors? We assume that the resulting model values will show whether a unifactorial model of health-related behavior is valid (in which case, it will be desirable to look for a universally acting latent factor) or multifactorial models are a better for description of health-related behavior (in which case, it will be desirable to look for different latent factors in the background for each kind of health-related behavior). The study was designed as a nonexperimental comparative study. ${ }^{20}$

\section{Materials}

We used the HRBS by Dosedlová et al. ${ }^{19}$ The scale was derived from methods for measuring health-related behavior used abroad and upon context analysis of responses gained from a set of 4,293 university students in $2005 .{ }^{19}$ This scale includes 42 items covering the key areas related to health: eating, drinking, sleep, daily regime, frequency of physical exercise, drug abuse, preventive measures, and mental hygiene. Items 1-32 were presented as statements (eg, "I eat at least 3 portions of fruit and vegetables every day"), which the respondent answered using a 5-point Likert scale ( $1=$ strongly agree, $5=$ strongly disagree). Questions 33-38 focused on how frequently some activities are pursued ("I eat fried foods"), and the respondents rated the frequency on a Likert scale ( $1=$ never, $5=$ very often). Items 39-42 covered the frequency of respondents' physical exercise (number of hours) and quantity of addictive substance use (alcohol and cigarettes). In these items, responses were recoded to produce five categories analogical to the 5-point scale from the previous parts of the questionnaire. The sum score converted to a scale 1-5 served as an auxiliary indicator of the total level of health-related behavior - the lower the value, the more beneficial the behavior and vice versa.

\section{Procedure}

A combination of several different nonprobability sampling methods were used. The respondents were selected and contacted by random selection from our extensive email database. A call for collaboration was published on social networks, and snowball sampling with personal contacts was used. Data collection took place over 10 months. The respondents were asked to fill out a battery of surveys. The surveys were available in two forms: pencil-and-paper and online. Respondents had a choice of format; 816 respondents filled out an online form, and 848 respondents opted for pencil-and-paper (the preference of pencil-and-paper increased with age). Penciland-paper data were manually digitized.

\section{Research sample}

The research sample consisted of 1,664 respondents. Inclusion criteria were: age $\geq 18$ years, citizen of the Czech Republic, healthy enough to complete the research tasks, and willful consent to participate in the research. There were more women in the research sample (see Table 1).

In terms of education, high school education was most frequent ( $45 \%$ ) followed by university (31\%) and elementary education $(\sim 10 \%)$. Educational structure was the same for both sexes. Structure of the sample in terms of habitat size and social status also showed a corresponding distribution in both sexes. In terms of economic activity, approximately half of the sample was represented by economically inactive persons (students and retirees) and half by economically active (working) persons. Approximately one-third of the sample was religious believers (30.8\% men and $39.8 \%$ women).

\section{Data analysis Internal factor structure of health behavior}

The aim of the first stage was to detect the internal factorial health behavior structure for the HRBS. The factor analysis method was used, which allowed for analyzing correlations of a greater number of measured (manifest) variables. This analysis determined the groups of variables that showed a statistically "close relationship" (ie, those based on a common latent variable). The suitability for factor analysis was verified by a Kaiser-Meyer-Olkinov value calculation $(\mathrm{KMO}=0.869)$. The number of factors was determined with an eigenvalue $>1$. Factors were extracted using maximum likelihood estimation with nonorthogonal Oblimin rotation,

Table I Research sample in terms of age: descriptive statistics $(\mathrm{N}=\mathrm{I}, 664)$

\begin{tabular}{|l|l|l|l|l|l|}
\hline & N & Min & Max & m & SD \\
\hline Men & 536 & 18 & 88 & 34.27 & 15.375 \\
Women & 1,128 & 18 & 93 & 35.96 & 16.474 \\
Total & 1,664 & & & 35.43 & 16.143 \\
\hline
\end{tabular}


which is suitable for situations in which the data suggest that the factors are probably not independent.

\section{Latent factor analysis}

The aim of the second stage was to test whether there was one common latent factor or multiple latent factors underlying the observed behaviors. The method of confirmatory factor analysis was applied. Models were created using the Lavaan package $^{21,22}$ under the GNU license.

\section{Ethics approval}

Research was conducted according to ethical principles. Participation was voluntary, and there was no risk of harm to the participants. Respondents signed informed consent to partici- pate in the study. The data obtained were treated as sensitive data according to Act No. 101/2000 Coll. In accordance with the internal regulations of Masaryk University, the Vice-Dean for Research assessed the compliance with ethical principles in this noninvasive research study and Development of Faculty of Arts Masaryk university professor Lukáš Fasora, who on May 24, 2018 confirmed that the research has been, met ethical standards. Compliance with ethical principles during the research project solution and in the submitted study was further assessed at the meeting of the Ethical committee of the Psychological institute Faculty of Art Masaryk University (the workplace of the solver) took place on October 23, 2018. Commission members, Prof. Blatný, Dr Klimusová, and Dr Jelinek, confirmed compliance with ethical principles.

Table 2 HRBS: item factor loadings $(\mathrm{N}=1,664)$

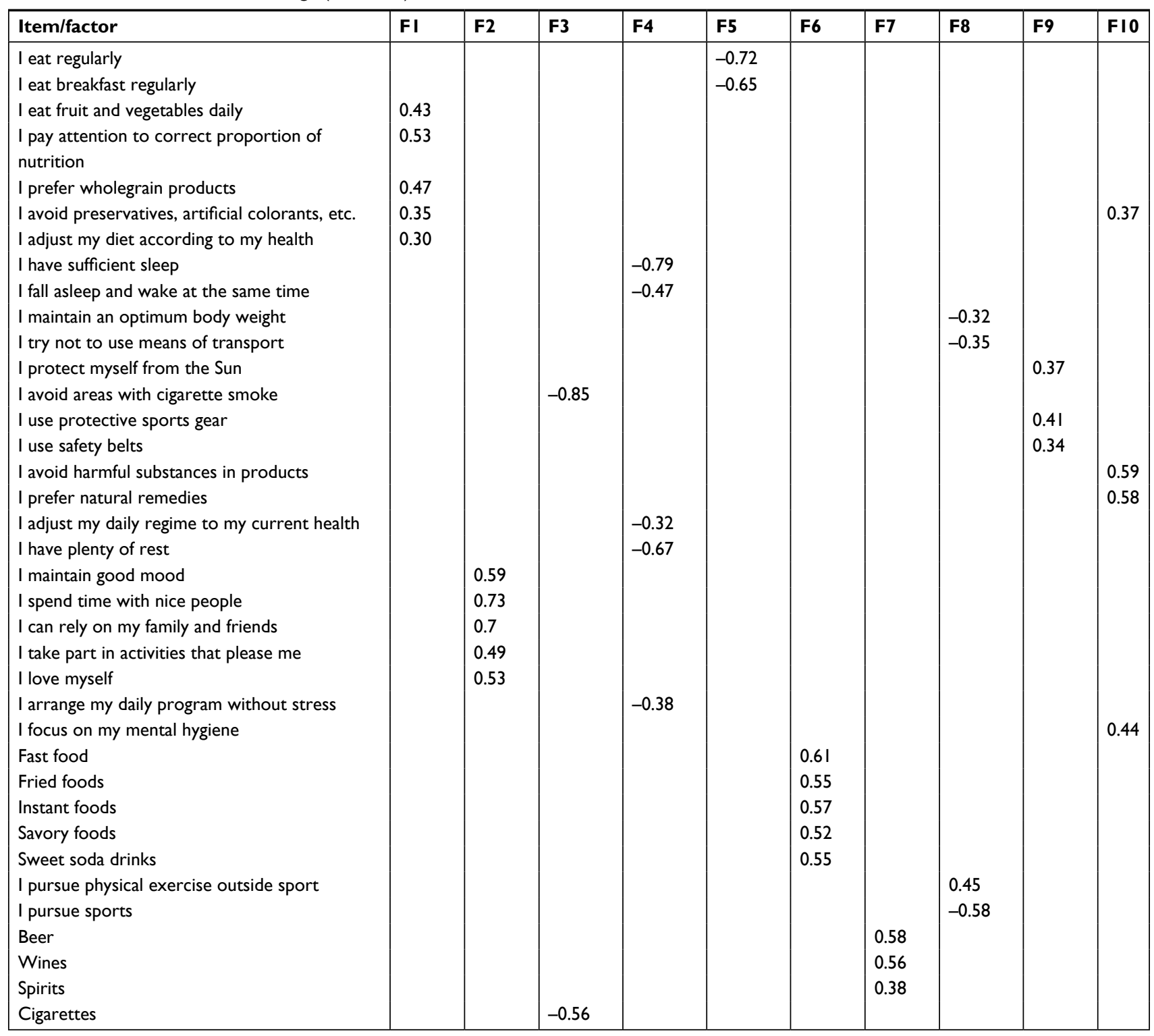




\section{Results}

\section{Internal factor structure of health behavior}

Ten factors were extracted (see Table 2) explaining 38.58\% of dispersion in the data. The items that did not saturate any of the factors by a charge exceeding 0.2 were eliminated from further analysis.

The reliability of extracted factors was verified, and factors were assigned names representing their content. The following table shows Cronbach's alpha values and the names of the ten extracted factors, see Table 3 . Scale reliability $(\mathrm{N}=10$ factors) was $a=0.731$.

\section{Latent variable analysis}

Four models were compared in which observed (endogenous) variables were created from the ten factors extracted during Phase I. Latent factor structure was verified that presumed the existence of one latent factor (HB) in model M1, and model M2 worked with the assumption of two theoretically

Table 3 Extracted factors of health-related behavior: reliability $(\mathrm{N}=\mathrm{I}, 664)$

\begin{tabular}{|l|l|l|}
\hline Extracted factor & Name & Cronbach's $\boldsymbol{\alpha}$ \\
\hline FI & Healthy eating & 0.709 \\
F2 & Positive experiences & 0.773 \\
F3 & Habits - smoking & 0.641 \\
F4 & Daily regime & 0.721 \\
F5 & Eating regime & 0.675 \\
F6 & Unhealthy eating & 0.725 \\
F7 & Alcohol abuse & 0.535 \\
F8 & Physical activity and exercise & 0.452 \\
F9 & Use of protective gear & 0.676 \\
FI0 & Avoiding harmful substances & 0.676 \\
\hline
\end{tabular}

Table 4 Allocation of health behavior factors in the four tested models

\begin{tabular}{|l|l|l|l|l|}
\hline & MI & M2 & M3 & M4 \\
\hline FI Healthy eating & HB & HEB & HDB & DI \\
F2 Positive experiences & HB & HEB & HEB & D2 \\
F3 Habits - smoking & HB & HIB & HIB & D3 \\
F4 Daily regime & HB & HEB & HEB & D2 \\
F5 Eating regime & HB & HEB & HEB & D2 \\
F6 Unhealthy food & HB & HIB & HIB & DI \\
F7 Alcohol abuse & HB & HIB & HIB & D3 \\
F8 Physical activity and exercise & HB & HEB & HDB & D2 \\
F9 Use of protective gear & HB & HEB & HDB & D2 \\
F10 Avoiding harmful substances & HB & HEB & HDB & DI \\
\hline
\end{tabular}

Abbreviations: $\mathrm{HB}$, health-behavior; $\mathrm{HEB}$, health-enhanced behavior; HIB, healthimpaired behavior; HDB, health-directed behavior. derived factors (HEB and HIB). Model M3 involved a third factor (HDB), and model M4 verified the existence of three latent factors (D1, D2, and D3) derived statistically by means of exploratory factor analysis. For distribution details, see Table 4.

The fourth model (M4) worked with latent factors generated ex post with a statistical approach by means of factor analysis, as we presumed the existence of latent factors. The variables entered into the analysis were ten factors of the first order (see above). $\mathrm{KMO}=0.791$ confirmed the suitability of the data for factor analysis. The number of factors was determined mathematically (eigenvalue $>1$ ). Factors were extracted by means of principal component analysis with Varimax orthogonal rotation, minimizes the number of variables having high loads with each common factor and tends not to create one general factor. Three components (D1=eating, D2=regime adjustment, and D3=addictive drugs) were extracted that explained $54.6 \%$ of variance in the data.

Four models were created; their parameters are listed in Table 5. The values show that all of the tested models fulfilled the criteria for a good model.

Table 6 shows the degree of explaining ten health-related factors in the four tested models.

The resulting values clearly show that all four tested models demonstrated very similar values of the measured indicators (differences in millesimal order). This leads us to conclude that, underlying the ten extracted factors, there is probably one common latent factor that could be divided into a different number of partial latent (mutually correlated) factors depending on one's interpretation.

It is also apparent that, in all four tested models, latent variables explained the alcohol abuse factor significantly less than other factors. Behaviors that cover this factor deserve special attention and should be the subject of further research.

\section{Discussion}

The aim of the study was to test whether the measured manifestations of health-related behavior could be explained by the existence of a single common latent factor or if there is any evidence of multiple independent latent factors related to health behavior. The results of confirmatory factor analysis lead us to conclude that the studied health-related behaviors could be satisfactorily explained by one common latent factor, and dividing it into multiple factors did not yield qualitatively different results.

This conclusion conforms to the predictions of other authors. For instance, Donovan et a $1^{13}$ explicitly stated that there was one latent factor underlying the forms of healthrelated behavior that he studied. Several other authors worked 
Table 5 Indicators of good compliance for the four tested models

\begin{tabular}{|c|c|c|c|c|c|c|c|c|c|}
\hline Model title & Model source & NLF & $\chi^{2}$ & $d f$ & $P$-value & RMSEA & SRMR & CFI & TLI \\
\hline $\mathrm{MI}(\mathrm{HB})$ & Basic & I & |55.7| & 23 & 0.000 & 0.059 & 0.035 & 0.955 & 0.912 \\
\hline M2 (HEB+HIB) & Theory-based & 2 & 144.84 & 22 & 0.000 & 0.058 & 0.034 & 0.958 & 0.915 \\
\hline M3 (HEB+HIB+HDB) & Theory-based & 3 & $|48.5|$ & 20 & 0.000 & 0.062 & 0.034 & 0.956 & 0.902 \\
\hline M4 (DI+D2+D3) & Statistics-based & 3 & 146.64 & 20 & 0.000 & 0.062 & 0.034 & 0.957 & 0.903 \\
\hline
\end{tabular}

Note: The best result is shown in bold.

Abbreviations: CFI, Comparative Fit Index; df, degrees of freedom; HB, health behavior; HEB, health-enhanced behavior; HIB, health-impaired behavior; HDB, healthdirected behavior; NLF, number of latent factors; RMSEA, root mean square error of approximation; SRMR, Standardized Root Mean Square Residual; TLI, Tucker-Lewis index.

Table 6 Relation between the observed and latent factors in the four tested models: standardized estimate $\gamma$

\begin{tabular}{|l|l|l|l|l|}
\hline & $\gamma$ MI & $\gamma$ M2 & $\gamma$ M3 & $\gamma$ M4 \\
\hline FI Healthy eating & 0.597 & $\mathbf{0 . 6 0 2}$ & 0.588 & 0.518 \\
F2 Positive experiences & 0.329 & 0.334 & $\mathbf{0 . 3 3 9}$ & 0.315 \\
F3 Habits - smoking & 0.389 & 0.420 & 0.439 & $\mathbf{0 . 5 4 0}$ \\
F4 Daily regime & 0.519 & $\mathbf{0 . 5 2 1}$ & 0.510 & 0.520 \\
F5 Eating regime & 0.415 & $\mathbf{0 . 4 2 5}$ & 0.403 & 0.389 \\
F6 Unhealthy food & 0.431 & $\mathbf{0 . 4 7 2}$ & 0.460 & 0.376 \\
F7 Alcohol abuse & 0.111 & 0.133 & 0.135 & $\mathbf{0 . 1 5 8}$ \\
F8 Physical activity and exercise & 0.507 & $\mathbf{0 . 5 1 3}$ & 0.505 & 0.498 \\
F9 Use of protective gear & 0.453 & $\mathbf{0 . 4 5 6}$ & 0.456 & 0.439 \\
F10 Avoiding harmful substances & 0.546 & $\mathbf{0 . 5 9 6}$ & 0.541 & 0.483 \\
\hline
\end{tabular}

Note: The best result is shown in bold.

with the total scores of scales measuring different forms of health-related behaviors, which demonstrates a unifactorial approach to health-related behavior. ${ }^{23,24}$ Some authors demand a unifactorial model due to theoretical as well as pragmatic reasons. Evers and Quintiliani, ${ }^{25}$ for instance, sought mutually correlated dimensions in multidimensional models with the aim of finding the broadest possible behavioral model, as such a model would allow for reducing costs while preserving potentially high efficiency of processes and interventions focused on changing the behavior patterns toward the preservation of health-protecting behavior. The feasibility of such multidimensional change was experimentally confirmed in patients with colorectal cancer. ${ }^{26}$ Walsh et al ${ }^{27}$ demonstrated that participants who underwent challenging mental tasks during an experiment showed improvement in health-related behavior. There is much evidence that a generalized unifactorial view of health-related behavior is advisable. As Evers and Quintiliani ${ }^{25}$ stated, there is statistical evidence that various factors of the first order of health-related behavior demonstrate close mutual relations, which our study showed as well. It has repeatedly been confirmed that a change of one dimension brings changes in other health-related behavior dimensions.

Nonzero covariance of the latent factors in the tested models attests to mutually closer relationships between the tested latent factors. The lowest covariance, and the lowest standardized estimate of the latent variable's influence on the measured variable, was repeatedly found in all tested models for the alcohol consumption factor. We detected three causes. First, it might be an indication of this factor's independence from other manifestations of health-related behavior. However, the results of several studies oppose such an interpretation - for example, Noble et $\mathrm{al}^{28}$ confirmed a close relationship between SNAP variables (smoking, nutrition, alcohol, and physical inactivity) in a systematic review. Second, the finding might have been caused by the formulation of items in the questionnaire that asked for an average number of alcohol units consumed over the past week. According to current research, it is becoming clear that, in relation to alcohol, it is convenient to differentiate at least three behavioral patterns: the use of small amounts of alcohol, excessive drinking, and so-called binge drinking, each of which brings provably different health risks. ${ }^{29,30} \mathrm{~A}$ reformulation of item 41 in the HRBS could be considered to better differentiate between the described three forms of alcohol-related behavior. And third, other groups of research that differentiate and analyze the consumption of wine separately from drinking beer-based alcohol (or in combination with spirits) have concluded that patterns of behavior and consequences of health-related behavior differ between these two groups. It was shown, for instance, that moderate wine drinkers have 5 years longer life expectancy than beer drinkers. ${ }^{31}$ The findings shows that it seems convenient to divide the alcohol consumption factor into two separate types of behavior - wine drinking and beer drinking (or drinking spirits) - and to reconsider the formulation of items measuring the consumption of these beverages.

Our study showed that two or three differently arranged latent factors preserved almost identical statistical parameters of the entire model. A differentiation of various types of health-related behavior did not yield any added value in statistical terms, but as other published studies showed, such differentiation might provide an equally good framework for more detailed analyses and interpretations. Cluster 
analysis-based studies could be listed as examples ${ }^{11,17,32-35}$ that demonstrate the advisability of differentiating between health-related behaviors due to both theory and practice. Lifestyle tends to be a frequently mentioned latent variable underlying health behaviors. ${ }^{1-4,9,11-13,15,23,24,30,32,33,36,38-40} \mathrm{We}$ conclude our study with a frequently cited statement ${ }^{36-40}$ by Pender: "Health-promoting lifestyle is a multidimensional pattern of behavior aimed at maintaining or improving wellbeing and personal self-fulfillment" or a "multidimensional file of activities pursued from one's own initiative." 41

\section{Conclusion}

In health research, it is beneficial to observe various forms of behavior that lead to promoting, maintaining, or impairing health. The obtained results show that various forms of health-related behavior have a close mutual relationship, with the exception of behavior related to alcohol consumption. There is probably one common latent factor underlying the various forms of health behavior. Differentiation to multiple latent factors yielded neither any significant improvement of statistical traits nor its significant reduction, which leads us to the conclusion that one common latent factor might consist of multiple independent mutually partial units that are closely related. The obtained results provide space for further research, specifically the extension of tested models by bio-psycho-social moderators and mediators.

\section{Acknowledgments}

Thanks to the authors of the Lavaan program, to Jiří Haviger for data handling, and to all participants. This research was funded by the Czech Science Foundation (GACR), project number GA13-19808S, "Health-Enhancing and Health-Threatening Behavior: Determinants, Models, and Consequences."

\section{Disclosure}

The authors report no conflicts of interest in this work.

\section{References}

1. Sallis JF, Owen N, Fisher EB. Ecological model of health behavior. In: Glanz K, Rimer BK, Viswanath K, editors. Health Behavior and Health Education: Theory, Research and Practice. 4th ed. San Francisco: A Willey Imprint; 2008:465-482.

2. Brannon L, Feist J. Health Psychology: An Introduction to Behavior and Health. 8th ed. Belmont: Cengage Learning; 2014.

3. Steptoe A, Wardle J. Health related behavior: prevalence and links with disease. In: Kaptein AA, Weinman J, editors. Health Psychology. Oxford, UK: The British Psychological Society and Blackwell Publishing; 2004:21-51.

4. von Ah D, Ebert S, Ngamvitroj A, Park N, Kang DH. Predictors of health behaviours in college students. $J$ Adv Nurs. 2004;48(5):463-474.
5. Potard C, Courtois R, Rusch E. The influence of peers on risky sexual behaviour during adolescence. Eur J Contracept Reprod Health Care. 2008;13(3):264-270.

6. Bélanger A, Hudon C, Fortin M, Amirall J, Bouhali T, Chouinard MC. Validation of a French-language version of the health education impact Questionnaire (heiQ) among chronic disease patients seen in primary care: a cross-sectional study. Health Qual Life Outcomes. 2015;13:64-75.

7. Montano DE, Kasprzyk D. Theory of reasoned action, theory of planned behavior, and the integrated behavioral model. In: Glanz K, Rimer BK, Viswanath K, editors. Heath Behavior: Theory, Research, and Practice. San Francisco: Willey; 2015:67-96.

8. Pitts N. Detection, Assessment, Diagnosis and Monitoring of Caries. Basel: S. Karger AG; 2009.

9. Glanz K, Rimer BK, Lewis F. Health Behavior and Health Education San Francisco: Wiley; 2002.

10. Sharma M. Multi-theory model (MTM) for health behavior change. Webmed Central Behav. 2015;6(9):WMC004982.

11. Lippke S, Nigg CR, Maddock JE. Health-promoting and health-risk behaviors: theory-driven analyses of multiple health behavior change in three international samples. Int J Behav Med. 2012;19(1):1-13.

12. Hilliard ME, Riekert KA, Ockene JK, Pbert L. The Handbook of Health Behavior Change. 5th ed. New York: Springer; 2018.

13. Donovan JE, Jessor R, Costa FM. Structure of health-enhancing behavior in adolescence: a latent-variable approach. $J$ Health Soc Behav. 1993;34(4):346-362.

14. Goldenson NI, Kirkpatrick MG, Leventhal AM. Initial Validation of the Pleasure and Health Behavior Inventory - a measure of motivation to engage in health-damaging behavior to overcome deficient pleasure. Am J Health Behav. 2015;39(5):652-664.

15. Glanz K, Rimer BK, Viswanath K. Heath Behavior: Theory, Research, and Practice. San Francisco: Willey; 2015.

16. Skalamera J, Hummer RA. Educational attainment and the clustering of health-related behavior among U.S. young adults. Prev Med. 2016;84:83-89.

17. Spengler S, Mess F, Mewes N, Mensink GB, Woll A. A cluster-analytic approach towards multidimensional health-related behaviors in adolescents: the MoMo-study. BMC Public Health. 2012;12:1128-1135.

18. Strecher VJ, Devellis BM, Becker MH, Rosenstock IM. The role of self-efficacy in achieving health behavior change. Health Educ $Q$. 1986;13(1):73-92.

19. Dosedlová J, Slováčková Z, Klimusová H. Optimismem ke zdraví? Kognitivní a osobnostní determinanty zdraví podporujícího chování. [Health optimism? Cognitive and personality determinants of health promoting behavior]. Brno: Tribun EU; 2013.

20. Jackson DL, Gillaspy JA, Purc-Stephenson R. Reporting practices in confirmatory factor analysis: an overview and some recommendations. Psychol Methods. 2009;14(1):6-23.

21. Rosseel Y. Lavaan: an $R$ package for structural equation modeling. $J$ Stat Softw. 2012;48(2):1-36.

22. Hamilton WK. Lavaan Shiny: Latent Variable Analysis with Shiny. Stanford: University of California; 2016.

23. Hoerster KD, Lehavot K, Simpson T, Mcfall M, Reiber G, Nelson KM. Health and health behavior differences: U.S. Military, veteran, and civilian men. Am J Prev Med. 2012;43(5):483-489.

24. Szakály Z, Szente V, Kövér G, Polereczki Z, Szigeti O. The influence of lifestyle on health behavior and preference for functional foods. Appetite. 2012;58(1):406-413.

25. Evers KE, Quintiliani LM. Advances in multiple health behavior change research. Transl Behav Med. 2013;3(1):59-61.

26. Harper FW, Nevedal A, Eggly S, Francis C, Schwartz K, Albrecht TL. "It's up to you and God": understanding health behavior change in older African American survivors of colorectal cancer. Transl Behav Med. 2013;3(1):94-103.

27. Walsh JL, Senn TE, Carey MP. Longitudinal associations between health behaviors and mental health in low-income adults. Transl Behav Med. 2013;3(1):104-113. 
28. Noble N, Paul C, Turon H, Oldmeadow C. Which modifiable health risk behaviours are related? A systematic review of the clustering of smoking, nutrition, alcohol and physical activity ('SNAP') health risk factors. Prev Med. 2015;81:16-41.

29. Nordegren T. The A-Z Encyclopedia of Alcohol and Drug Abuse. Boca Raton: Brown Walker Press; 2002.

30. Koob G, LeMoal M, Thompson R. Encyclopedia of Behavioral Neuroscience. New York: Elsevier; 2010.

31. National Institute of Health. Health risks and benefits of alcohol consumption. Alcohol Res Health. 2000;24:5-11.

32. Allara E, Angelini P, Gorini G, et al. A prevention program for multiple health-compromising behaviors in adolescence: baseline results from a cluster randomized controlled trial. Prev Med. 2015;71:20-26.

33. Dosedlová J, Fialová L, Kebza V, Slováčková Z. Předpoklady zdraví a životní spokojenosti. [Prerequisites for Health and Life Satisfaction]. Brno: MSD; 2008.

34. Falkstedt D, Möller J, Zeebari Z, Engström K, Prevalence EK. Prevalence, co-occurrence, and clustering of health-risk behaviors among people with different socio-economic trajectories: a population-based study. Prev Med. 2016;93:64-69.
35. Mawditt C, Sacker A, Britton A, Kelly Y, Cable N. The clustering of health-related behaviours in a British population sample: testing for cohort differences. Prev Med. 2016;88:95-107.

36. Taylor NE. Role of biopsychosocial variables in predicting positive wellbeing and health-promoting behaviors in individuals with autoimmune diseases. Dissertation Abstr Int Sec B Sci Eng. 2008;69:3280.

37. Burns N, Grove SK. Understanding Nursing Research: Building An Evidence-Based Practice. 5th ed. Maryland: Heights: Elsevier Saunders; 2010.

38. Bryer J, Cherkis F, Raman J. Health-promotion behaviors of undergraduate nursing students: a survey analysis. Nurs Educ Perspect. 2013;34(6):410-415.

39. Kurt SA. The relationship between healthy lifestyle behaviors and health locus of control among nursing and midwifery students. Am J Nurs Res. 2015;3:36-40.

40. Murakami M, Mainen ZF. Preparing and selecting actions with neural populations: toward cortical circuit mechanisms. Curr Opin Neurobiol. 2015;33:40-46.

41. Gochman DS. Handbook of Health Behavior Research I: Personal and Social Determinants. New York: Plenum Press; 1997.
Psychology Research and Behavior Management

\section{Publish your work in this journal}

Psychology Research and Behavior Management is an international, peerreviewed, open access journal focusing on the science of psychology and its application in behavior management to develop improved outcomes in the clinical, educational, sports and business arenas. Specific topics covered in the journal include: Neuroscience, memory and decision making; Behavior

\section{Dovepress}

modification and management; Clinical applications; Business and sports performance management; Social and developmental studies; Animal studies. The manuscript management system is completely online and includes a very quick and fair peer-review system, which is all easy to use. Visit http://www. dovepress.com/testimonials.php to read real quotes from published authors. 